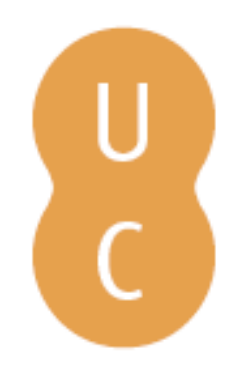

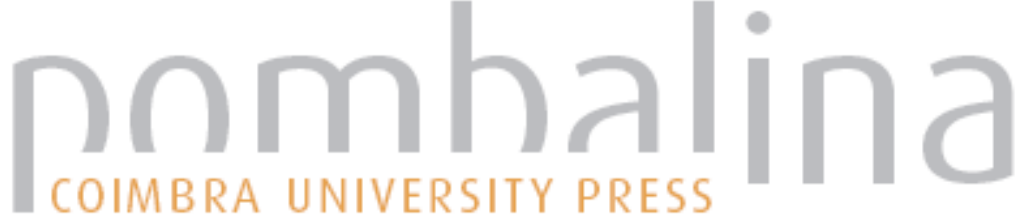

Mathematical modeling of the forest fires initiation, spread and impact on buildings

Autor(es): Perminov, Valeriy

Publicado por: Imprensa da Universidade de Coimbra

URL

persistente: URI:http://hdl.handle.net/10316.2/44606

DOI: $\quad$ DOI:https://doi.org/10.14195/978-989-26-16-506_89

Accessed : $\quad$ 26-Apr-2023 15:47:19

A navegação consulta e descarregamento dos títulos inseridos nas Bibliotecas Digitais UC Digitalis, UC Pombalina e UC Impactum, pressupõem a aceitação plena e sem reservas dos Termos e Condições de Uso destas Bibliotecas Digitais, disponíveis em https://digitalis.uc.pt/pt-pt/termos.

Conforme exposto nos referidos Termos e Condições de Uso, o descarregamento de títulos de acesso restrito requer uma licença válida de autorização devendo o utilizador aceder ao(s) documento(s) a partir de um endereço de IP da instituição detentora da supramencionada licença.

Ao utilizador é apenas permitido o descarregamento para uso pessoal, pelo que o emprego do(s) título(s) descarregado(s) para outro fim, designadamente comercial, carece de autorização do respetivo autor ou editor da obra.

Na medida em que todas as obras da UC Digitalis se encontram protegidas pelo Código do Direito de Autor e Direitos Conexos e demais legislação aplicável, toda a cópia, parcial ou total, deste documento, nos casos em que é legalmente admitida, deverá conter ou fazer-se acompanhar por este aviso. 


\section{ADVANCES IN}

\section{FOREST FIRE RESEARCH}

\section{8}

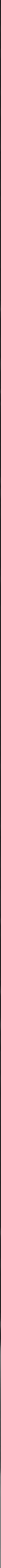




\title{
Mathematical modeling of the forest fires initiation, spread and impact on buildings
}

\author{
Valeriy Perminov \\ Tomsk Polytechnic University. Lenin Avenue. 30, 634050. Tomsk. Russia, \{perminov@tpu.ru\}
}

\begin{abstract}
The protection of buildings and structures in a community from destruction by fire is a very important concern. At present, fire services can forecast the danger rating of, or the specific weather elements relating to, forest fire. There is need to understand and predict forest fire initiation, behavior and impact of fire on the buildings and constructions. This paper's purposes are the improvement of knowledge on the fundamental physical mechanisms that control forest fire behavior. The mathematical modeling of forest fires actions on buildings and structures has been carried out to study the effects of fire intensity and wind speed on possibility of ignition of buildings. The modeling approach is based on the use of standard non-stationary threedimensional conservation equations that are solved numerically under the input conditions specific for large crown forest fires. A multiphase mathematical model of wind-aided crown forest fires propagating through heterogeneous fuel beds has been performed. It takes into account the hydrodynamic aspects of the flow and uses Arrhenius kinetics to describe the basic physics and chemical processes of thermal decomposition heating, drying, pyrolysis, and combustion. Turbulence and radiation are considered in order to improve the physical insight. It allows to investigate the dynamics of the impact of forest fires on buildings under the influence of various external conditions: a) meteorology conditions (air temperature, wind velocity etc.), b) type (various kinds of forest combustible materials) and their state (load, moisture etc.). The calculations let to get the maximum distance from the fire to the building in which the object possible ignition. It has been found that the effect of increasing the wind speed is to increase the safety distances between forest and building. The increasing of building height is observed also led to increase the safety distances between forest and building. Specific experiments are also needed to obtain more reliable information on validation of further solution of this problem. The paper was supported from RFBR (project code: № 16-41-700022 p_a) and within the framework of Tomsk Polytechnic University Competitiveness Enhancement Program grant.
\end{abstract}

Keywords: mathematical model, forest fire, crown, ignition, spread of fire, pyrolysis, combustion

\section{Introduction}

The protection of buildings and structures in a community from destruction by forest fire is a very important concern. At present, fire services can forecast the danger rating of, or the specific weather elements relating to forest fire. A great deal of work has been done on the theoretical problem of forest fires. The first accepted method for prediction of crown fires was given by Rothermal (1972) and Van Wagner (1977). The semi-empirical models allow to obtain a quite good data of the forest fire rate of spread as a function of fuel bulk and moisture, wind velocity and the terrain slope. But these models use data for particular cases and do not give results for general fire conditions. Also crown fires initiation and hazard have been studied and modeled in detail (eg: Alexander, 1979, Xanthopoulos, 1990, Van Wagner (1999), Cruz and et al., 2002, Albini, 1995, Scott and Reinhardt, 2001). A mathematical model of forest fires was obtained by Grishin (1997) based on an analysis of known and original experimental data, and using concepts and methods from reactive media mechanics. The physical two-phase models used by Morvan (2004) may be considered as a development and extension of the formulation proposed by Grishin. There is need to understand and predict forest fire initiation, behavior and impact of fire on the buildings and constructions. This paper's purposes are the improvement of knowledge on the fundamental physical mechanisms that control forest fire behavior.

Advances in Forest Fire Research 2018 - Page 808 
The mathematical modeling of forest fires actions on buildings and structures has been carried out to study the effects of fire intensity and wind speed on possibility of ignition of buildings. The dangerous distances between forest and buildings are calculated in cases when the buildings will be ignited under the influence of forest fires.

\section{Physical and mathematical model}

It is assumed that the forest during a forest fire can be modeled as 1) a multi-phase, multistoried, spatially heterogeneous medium; 2) in the fire zone the forest is a porous-dispersed, two-temperature, single-velocity, reactive medium; 3) the forest canopy is supposed to be non - deformed medium (trunks, large branches, small twigs and needles), which affects only the magnitude of the force of resistance in the equation of conservation of momentum in the gas phase, i.e., the medium is assumed to be quasi-solid (almost non-deformable during wind gusts); 4) let there be a so-called "ventilated" forest massif, in which the volume of fractions of condensed forest fuel phases, consisting of dry organic matter, water in liquid state, solid pyrolysis products, and ash, can be neglected compared to the volume fraction of gas phase (components of air and gaseous pyrolysis products); 5) the flow has a developed turbulent nature and molecular transfer is neglected; 6) gaseous phase density doesn't depend on the pressure because of the low velocities of the flow in comparison with the velocity of the sound. Let the point $x_{1}, x_{2}, x_{3}=0$ is situated at the center of the surface forest fire source at the height of the roughness level, axis $0 x_{1}$ directed parallel to the Earth's surface to the right in the direction of the unperturbed wind speed, axis $O x_{2}$ directed perpendicular to $O x_{1}$ and axis $0 x_{3}$ directed upward (Fig. 1). The building is situated on the right part of the picture.

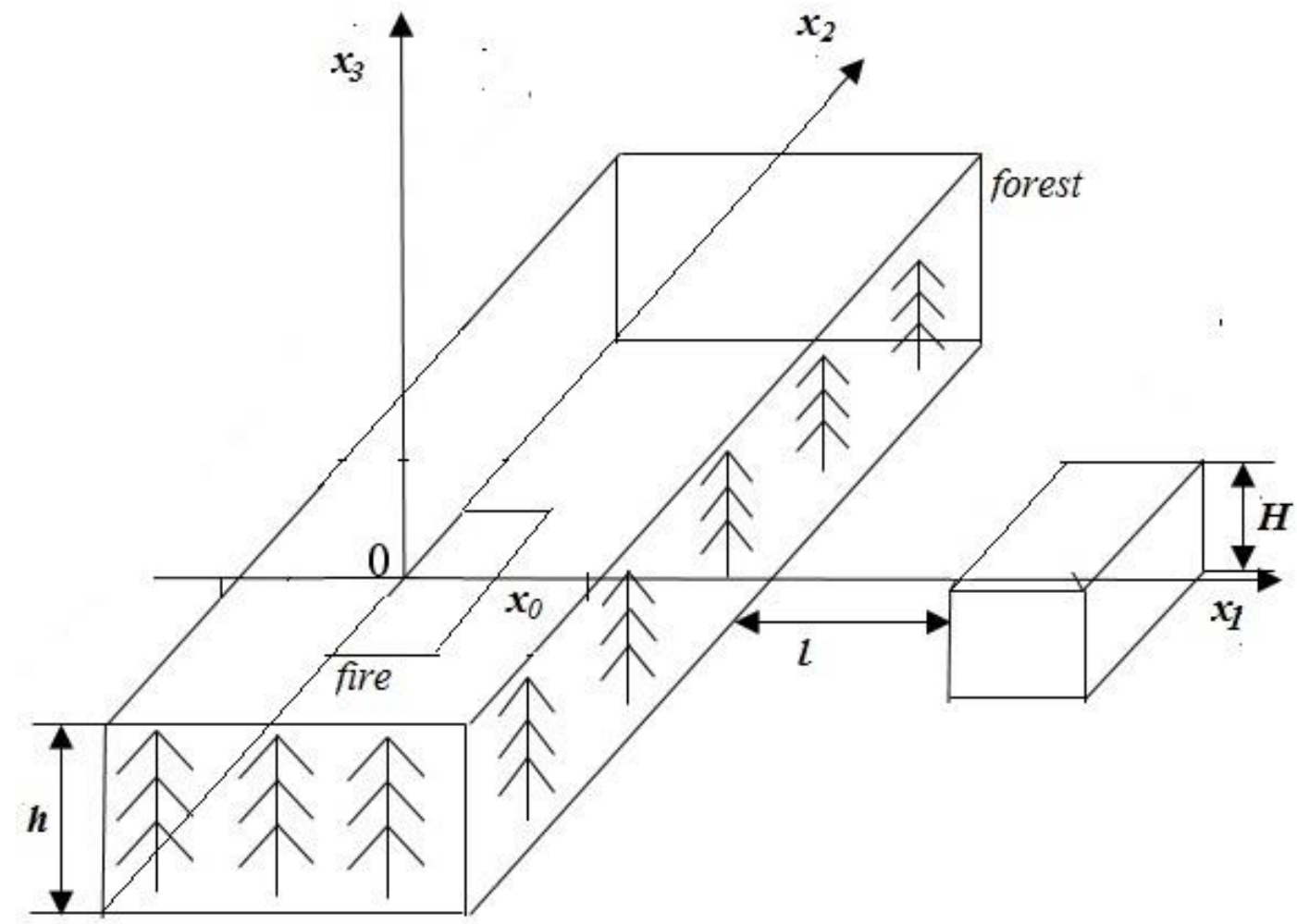

Figure 1 - The scheme of calculation domain.

Problem formulated above reduces to the solution of systems of equations (1)-(7): 
$\frac{\partial \rho}{\partial t}+\frac{\partial}{\partial x_{j}}\left(\rho v_{j}\right)=Q, j=\overline{1,3}, i=\overline{1,3}$

$\rho \frac{d v_{i}}{d t}=-\frac{\partial P}{\partial x_{i}}+\frac{\partial}{\partial x_{j}}\left(-\rho \vec{v}_{i}^{\prime} v_{j}\right)-\rho s c_{d} v_{i}|\vec{v}|-\rho g_{i}-Q v_{i} ;$

$\rho c_{p} \frac{d T}{d t}=\frac{\partial}{\partial x_{j}}\left(-\rho c_{p} v_{j}^{\prime} \overline{T^{\prime}}\right)+q_{5} R_{5}-\alpha_{v}\left(T-T_{s}\right)+k_{g}\left(c U_{R}-4 \sigma T^{4}\right) ;$

$\rho \frac{d c_{\alpha}}{d t}=\frac{\partial}{\partial x_{j}}\left(-\rho \overline{v_{j}^{\prime} c_{\alpha}^{\prime}}\right)+R_{5 \alpha}-Q c_{\alpha}, \alpha=1,2 ;$

$\frac{\partial}{\partial x_{j}}\left(\frac{c}{3 k} \frac{\partial U_{R}}{\partial x_{j}}\right)-k c U_{R}+4 k_{S} \sigma T_{S}^{4}+4 k_{g} \sigma T^{4}=0$,

$k=k_{g}+k_{S}$;

$$
\begin{aligned}
& \sum_{i=1}^{4} \rho_{i} c_{p i} \varphi_{i} \frac{\partial T_{S}}{\partial t}==q_{3} R_{3}-q_{2} R_{2}-k_{S}\left(c U_{R}-4 \sigma T_{S}^{4}\right)+\alpha_{v}\left(T-T_{S}\right) ; \\
& \rho_{1} \frac{\partial \varphi_{1}}{\partial t}=-R_{1 s}, \rho_{2} \frac{\partial \varphi_{2}}{\partial t}=-R_{2 s}, \rho_{3} \frac{\partial \varphi_{3}}{\partial t}=\alpha_{C} R_{1 s}-\frac{M_{C}}{M_{1}} R_{3 w}, \rho_{4} \frac{\partial \varphi_{4}}{\partial t}=0 ; \\
& \sum_{\alpha=1}^{3} c_{\alpha}=1, P_{e}=\rho R T \sum_{\alpha=1}^{3} \frac{c_{\alpha}}{M_{\alpha}}, \vec{v}=\left(v_{1}, v_{2}, v_{3}\right), \vec{g}=(0,0, g) .
\end{aligned}
$$

The system of equations (1)-(7) must be solved taking into account the initial and boundary conditions:

$$
\begin{gathered}
t=0: v_{1}=0, v_{2}=0, v_{3}=0, T=T_{e}, c_{\alpha}=c_{\alpha e}, T_{s}=T_{s e}, \varphi_{i}=\varphi_{i e} ; \\
x_{1}=0: v_{1}=V, v_{2}=0, v_{3}=0, T=T_{e}, c_{\alpha}=c_{\alpha e},-\frac{c}{3 k} \frac{\partial U_{R}}{\partial x_{1}}+\frac{c}{2} U_{R}=0 ; \\
x_{1}=x_{1 e}: \frac{\partial v_{1}}{\partial x_{1}}=0, \frac{\partial v_{2}}{\partial x_{1}}=0, \frac{\partial v_{3}}{\partial x_{1}}=0, \frac{\partial T}{\partial x_{1}}=0, \frac{\partial c_{\alpha}}{\partial x_{1}}=0, \frac{c}{3 k} \frac{\partial U_{R}}{\partial x_{1}}+\frac{c}{2} U_{R}=0 ; \\
x_{2}=-x_{2 e}: \frac{\partial v_{1}}{\partial x_{2}}=0, \frac{\partial v_{2}}{\partial x_{2}}=0, \frac{\partial v_{3}}{\partial x_{2}}=0, \frac{\partial T}{\partial x_{2}}=0, \frac{\partial c_{\alpha}}{\partial x_{2}}=0,-\frac{c}{3 k} \frac{\partial U_{R}}{\partial x_{2}}+\frac{c}{2} U_{R}=0 ; \\
x_{2}=x_{2 e}: \frac{\partial v_{1}}{\partial x_{2}}=0, \frac{\partial v_{2}}{\partial x_{2}}=0, \frac{\partial v_{3}}{\partial x_{2}}=0, \frac{\partial T}{\partial x_{2}}=0, \frac{\partial c_{\alpha}}{\partial x_{2}}=0, \frac{c}{3 k} \frac{\partial U_{R}}{\partial x_{2}}+\frac{c}{2} U_{R}=0 ; \\
x_{3}=0: v_{1}=0, v_{2}=0, \frac{\partial c_{\alpha}}{\partial x_{3}}=0,-\frac{c}{3 k} \frac{\partial U_{R}}{\partial x_{3}}+\frac{c}{2} U_{R}=0, \\
\rho v_{3}=\rho_{0} \omega_{0}, T=T_{0},\left|x_{1}\right| \leq x_{0},\left|x_{2}\right| \leq x_{0}, \\
\rho v_{3}=0, T=T_{e},\left|x_{1}\right|>x_{0},\left|x_{2}\right|>x_{0} ; \\
x_{3}=x_{3 e}: \frac{\partial v_{1}}{\partial x_{3}}=0, \frac{\partial v_{2}}{\partial x_{3}}=0, \frac{\partial v_{3}}{\partial x_{3}}=0, \frac{\partial T}{\partial x_{3}}=0, \frac{\partial c_{\alpha}}{\partial x_{3}}=0, \frac{c}{3 k} \frac{\partial U_{R}}{\partial x_{3}}+\frac{c}{2} U_{R}=0 .
\end{gathered}
$$


Here and above $\frac{\mathrm{d}}{\mathrm{d} t}$ is the symbol of the total (substantial) derivative; $\alpha_{v}$ is the coefficient of phase exchange; $\rho$ - density of gas - dispersed phase, $t$ is time; $v_{i}$ - the velocity components; $T, T_{S}$, temperatures of gas and solid phases, $U_{R}$ - density of radiation energy, $k$ - coefficient of radiation attenuation, $P$ - pressure; $c_{p}$ - constant pressure specific heat of the gas phase, $c_{p i}, \rho_{i}, \varphi_{\mathrm{i}}$ - specific heat, density and volume of fraction of condensed phase (1 - dry organic substance, 2 - moisture, 3 condensed pyrolysis products, 4 - mineral part of forest fuel), $R_{i}$ - the mass rates of chemical reactions, $q_{i}$ - thermal effects of chemical reactions; $k_{g}, k_{S}$ - radiation absorption coefficients for gas and condensed phases; $T_{e}$ - the ambient temperature; $c_{\alpha}$ - mass concentrations of $\alpha$ - component of gas dispersed medium, index $\alpha=1,2,3$ where 1 corresponds to the density of oxygen, 2 - to carbon monoxide $C O, 3$ - to carbon dioxide and inert components of air; $R$ - universal gas constant; $M_{\alpha}, M_{C}$, and $M$ molecular mass of $\alpha$-components of the gas phase, carbon and air mixture; $g$ is the gravity acceleration; $c_{d}$ is an empirical coefficient of the resistance of the vegetation, $s$ is the specific surface of the forest fuel in the given forest stratum. To define source terms which characterize inflow (outflow of mass) in a volume unit of the gas-dispersed phase, the following formulae were used for the rate of formulation of the gas-dispersed mixture $Q$, outflow of oxygen $R_{51}$, changing carbon monoxide $R_{52}$.

$$
\begin{aligned}
\dot{m} & =\left(1-\alpha_{c}\right) R_{1}+R_{2}+\frac{M_{c}}{M_{1}} R_{3}, \\
Q= & \left(1-\alpha_{c}\right) R_{1}+R_{2}+\frac{M_{c}}{M_{1}} R_{3}, R_{51}=-R_{3}-\frac{M_{1}}{2 M_{2}} R_{5}, R_{52}=v_{g}\left(1-\alpha_{c}\right) R_{1}-R_{5}, R_{53}=0 . \\
R_{1} & =k_{1} \rho_{1} \varphi_{1} \exp \left(-\frac{E_{1}}{R T_{S}}\right), R_{2}=k_{2} \rho_{2} \varphi_{2} T^{-0.5} \exp \left(-\frac{E_{2}}{R T_{S}}\right), R_{3}=k_{3} \rho \varphi_{3} S_{\sigma} c_{1} \exp \left(-\frac{E_{3}}{R T_{S}}\right), \\
R_{5} & =k_{5} M_{2}\left(\frac{c_{1} M}{M_{1}}\right)^{0.5}\left(\frac{c_{2} M}{M_{2}}\right) T^{-2.25} \exp \left(-\frac{E_{5}}{R T}\right) .
\end{aligned}
$$

The initial values for volume of fractions of condensed phases are determined using the expressions:

$$
\varphi_{1 e}=\frac{d\left(1-v_{z}\right)}{\rho_{1}}, \varphi_{2 e}=\frac{W d}{\rho_{2}}, \varphi_{3 e}=\frac{\alpha_{c} \varphi_{1 e} \rho_{1}}{\rho_{3}}
$$

where $d$-bulk density for surface layer, $v_{z}$ - coefficient of ashes of forest fuel, $W$ - forest fuel moisture content. It is supposed that the optical properties of a medium are independent of radiation wavelength (the assumption that the medium is "grey"), and the so-called diffusion approximation for radiation flux density were used for a mathematical description of radiation transport during forest fires. To close the system (1)-(7), the components of the tensor of turbulent stresses, and the turbulent heat and mass fluxes are determined using the local-equilibrium model of turbulence (Grishin, 1997). The system of equations (1)-(7) contains terms associated with turbulent diffusion, thermal conduction, and convection, and needs to be closed. The components of the tensor of turbulent stresses $\rho \overline{v_{i}^{\prime} v_{j}^{\prime}}$, as well as the turbulent fluxes of heat and mass $\overline{\rho v_{j}^{\prime} c_{p} T^{\prime}}, \overline{\rho v_{j}^{\prime} c_{\alpha}^{\prime}}$ are written in terms of the gradients of the average flow properties using the formulas 


$$
\begin{aligned}
& -\rho \overline{v_{i} v_{j}}=\mu_{t}\left(\frac{\partial v_{i}}{\partial x_{j}}+\frac{\partial v_{j}}{\partial x_{i}}\right)-\frac{2}{3} K \delta_{i j},-\rho \overline{v_{j} c_{p} T^{\prime}}=\lambda_{t} \frac{\partial T}{\partial x_{j}},-\rho \overline{v_{j} c_{\alpha}^{\prime}}=\rho D_{t} \frac{\partial c_{\alpha}}{\partial x_{j}} \\
& \lambda_{t}=\mu_{t} c_{p} / \operatorname{Pr}_{t}, \rho D_{t}=\mu_{t} / S c_{t}, \mu_{t}=c_{\mu} \rho K^{2} / \varepsilon
\end{aligned}
$$

where $\mu_{t}, \lambda_{t}, D_{t}$ are the coefficients of turbulent viscosity, thermal conductivity, and diffusion, respectively; $\mathrm{Pr}_{t}, \mathrm{Sc}_{\mathrm{t}}$ are the turbulent Prandtl and Schmidt numbers, which were assumed to be equal to 1 . In dimensional form, the coefficient of dynamic turbulent viscosity is determined using local equilibrium model of turbulence (Grishin, 1997). The length of the mixing path is determined using the formula $l=x_{3} k_{t} /\left(1+2.5 x_{3} \sqrt{c_{d} s / h}\right)$ taking into account the fact that the coefficient of resistance $\mathrm{c}_{\mathrm{d}}$ in the space between the ground cover and the forest canopy base is equal to zero, while the constants $\mathrm{k}_{\mathrm{t}}=0.4$ and $\mathrm{h}=\mathrm{h}_{2}-\mathrm{h}_{1}\left(\mathrm{~h}_{2}, \mathrm{~h}_{1}-\right.$ height of the tree crowns and the height of the crown base $)$. It should be noted that this system of equations describes processes of transfer within the entire region of the forest massif, which includes the space between the underlying surface and the base of the forest canopy, the forest canopy and the space above it, while the appropriate components of the data base are used to calculate the specific properties of the various forest strata and the near-ground layer of atmosphere. This approach substantially simplifies the technology of solving problems of predicting the state of the medium in the fire zone numerically. The thermodynamic, thermophysical and structural characteristics correspond to the forest fuels in the canopy of a different (for example pine) type of forest.

\section{Numerical solution and results}

The boundary-value problem (1)-(14) is solved numerically. A discrete analog was obtained by means of the control volume method using the SIMPLE like algorithm (Patankar, 1981). Difference equations that arise in the course of sampling were resolved by the method of SIP (Patankar, 1981). In order to efficiently solve this problem in a reactive flow the method of splitting according to physical processes was used. The basic idea of this method is based on the information that the physical timescale of the processes is great than chemical. In the first stage, the hydrodynamic pattern of flow and distribution of scalar functions was calculated. Then the system of ordinary differential equations of chemical kinetics obtained as a result of splitting was then integrated. The time step for integrating each function has to be smaller than the characteristic time of physical process to ensure the convergence of the numerical method. The time step was selected automatically. The accuracy of the program was checked by the method of inserted analytical solutions. Analytical expressions for the unknown functions were substituted in (1)-(14) and the closure of the equations were calculated. This was then treated as the source in each equation. Next, with the aid of the algorithm described above, the values of the functions used were inferred with an accuracy of not less than $1 \%$. The effect of the dimensions of the control volumes on the solution was studied by diminishing them. Fields of temperature, velocity, component mass fractions, and volume fractions of phases were obtained numerically. The first stage is related to increasing maximum temperature in the place of ignition with the result that a crown fire source appears. At this process stage over the fire source a thermal wind is formed a zone of heated forest fire pyrolysis products which are mixed with air, float up and penetrate into the crowns of trees. As a result, forest fuels in the tree crowns are heated, moisture evaporates and gaseous and dispersed pyrolysis products are generated. Ignition of gaseous pyrolysis products of the crown occurs at the next stage, and that of gaseous pyrolysis products in the forest canopy occurs at the last stage. As a result of heating of forest fuel elements of crown, moisture evaporates, and pyrolysis occurs accompanied by the release of gaseous products, which then ignite and burn away in the forest canopy. At the moment of ignition, the gas combustible products of pyrolysis burn away, 
and the concentration of oxygen is rapidly reduced. The temperatures of both phases reach a maximum value at the point of ignition. The ignition processes is of a gas - phase nature. At $V \neq 0$, the wind field in the forest canopy interacts with the gas-jet obstacle that forms from the forest fire source and from the ignited forest canopy and burn away in the forest canopy. The isotherms of gas phase components moved in the forest canopy by the action of wind. It is concluded that the forest fire begins to spread. The results of the calculation give an opportunity to consider forest fire spread for different wind velocity, canopy bulk densities and moisture forest fuel. It is considered the effect of forest fire front on the building which is situated near from the forest. The influences of wind velocity and distance between forest and building on ignition of building are studied numerically. The results of calculations can be used to evaluate the thermal effects on the building, located near from the forest fires. The temperature fields of crown forest fire at definite moment will be interacted with the obstacle - building (Figure 2 a) and b)) and ignited it. Fig.2. shoes temperature field at the initial moment of forest fire spread for a wind speed of $15 \mathrm{~m} / \mathrm{s}$.

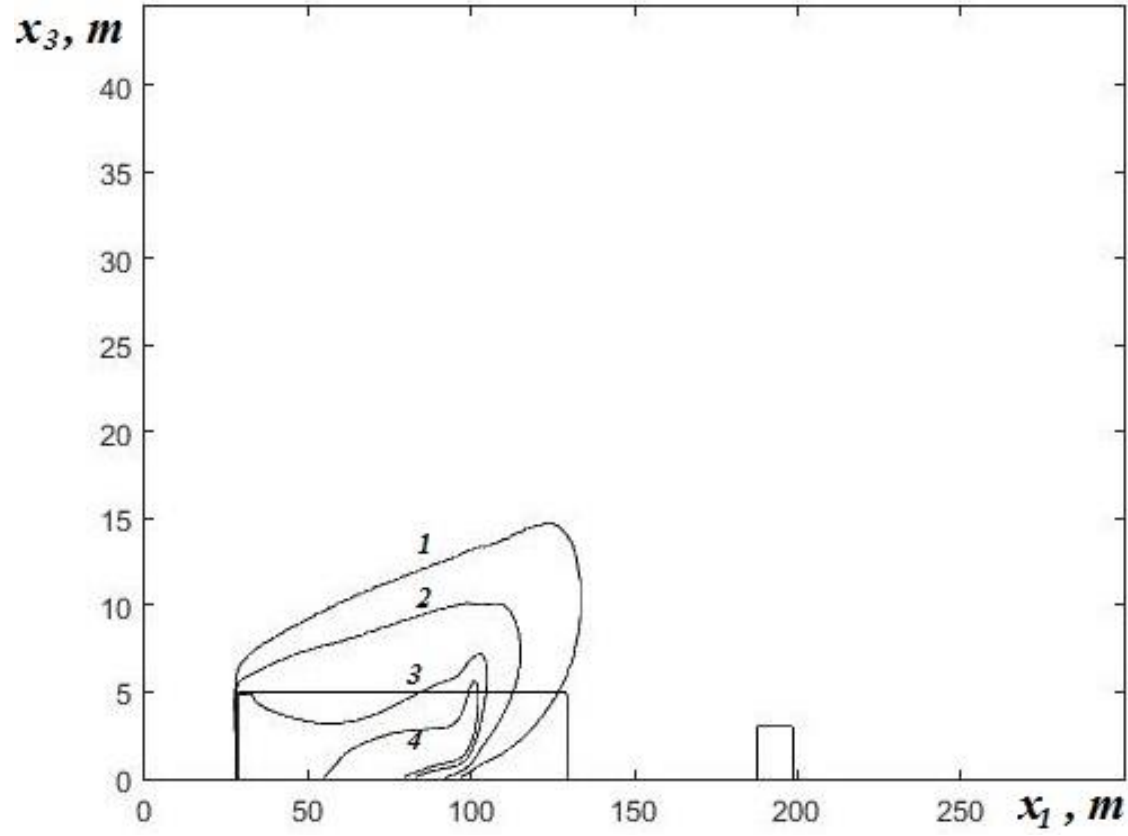

Fiure 2 - Gas temperature field at $t=15 \mathrm{~s}$ for a wind speed of $15 \mathrm{~m} / \mathrm{s} ; 1-1.5,2-2 ., 3-3 ., 4-4 ; \bar{T}=T / T_{e}, \bar{T}_{S}=T_{S} / T_{e}$, $T_{e}=300 K$.

During this process, the surface of the wall of the building heats as a result of convection and radiation heat transfer. The wood building will be ignited at definite temperature. It depends on wind velocities, distances from the forest fire to building, the height of building and others parameters. The Figures 3-5 represent the predicted distributions of temperature on the surfaces of the wall of the building as a function of vertical coordinate for the three selected wind speed values and different distances between forest and building. In paper Valendik and et al. (1979) it is showed that the wood will be ignited when its temperature exceeds 300C. The results of calculations presented on Figures 3 5 show that the surface temperature reach these values at wind velocities more than $6 \mathrm{~m} / \mathrm{s}$. The height of building in these calculations was $H=3 \mathrm{~m}$. 
Advances in Forest Fire Research 2018 - D. X. Viegas (Ed.)

Chapter 4 - Fire at the Wildland Urban Interface

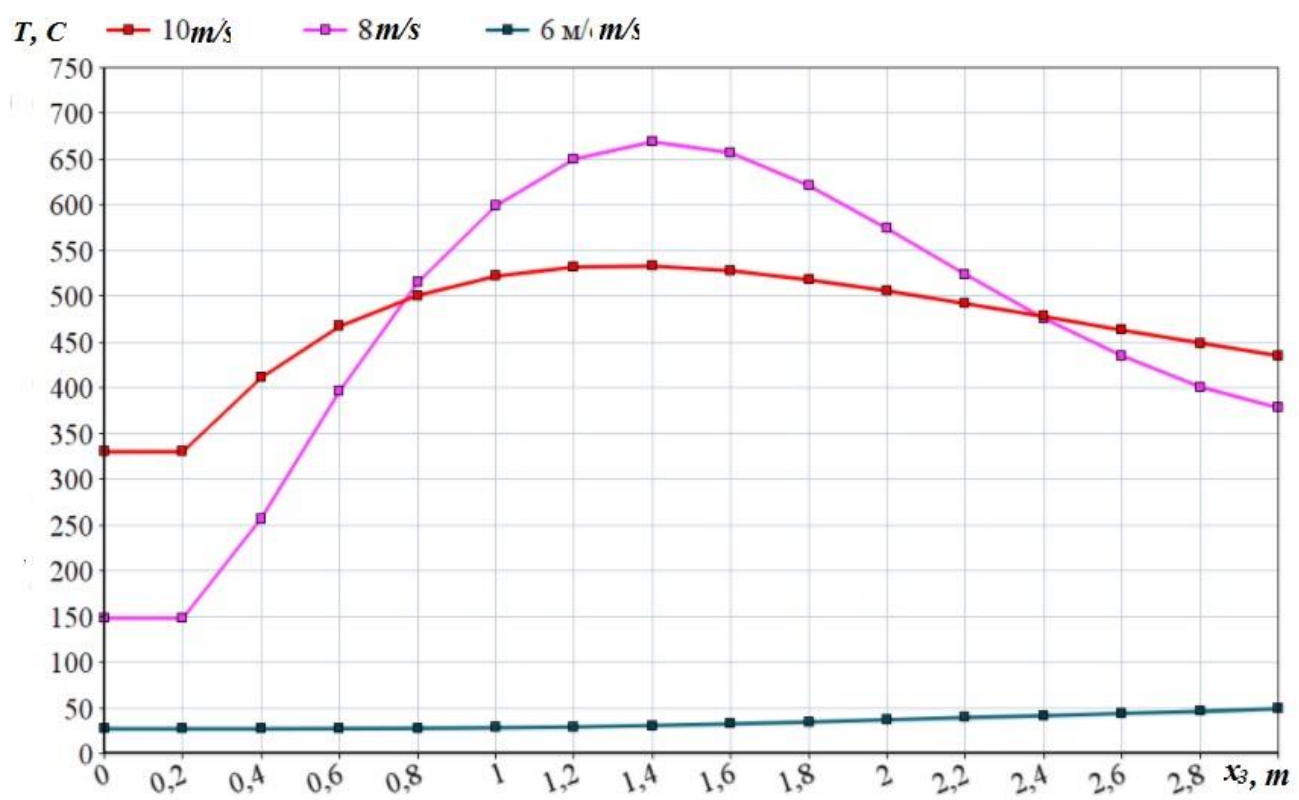

Figure 3 - The distribution of temperature on the wall of the building for three wind speed values. The distance between forest and building is $21 \mathrm{~m}$.

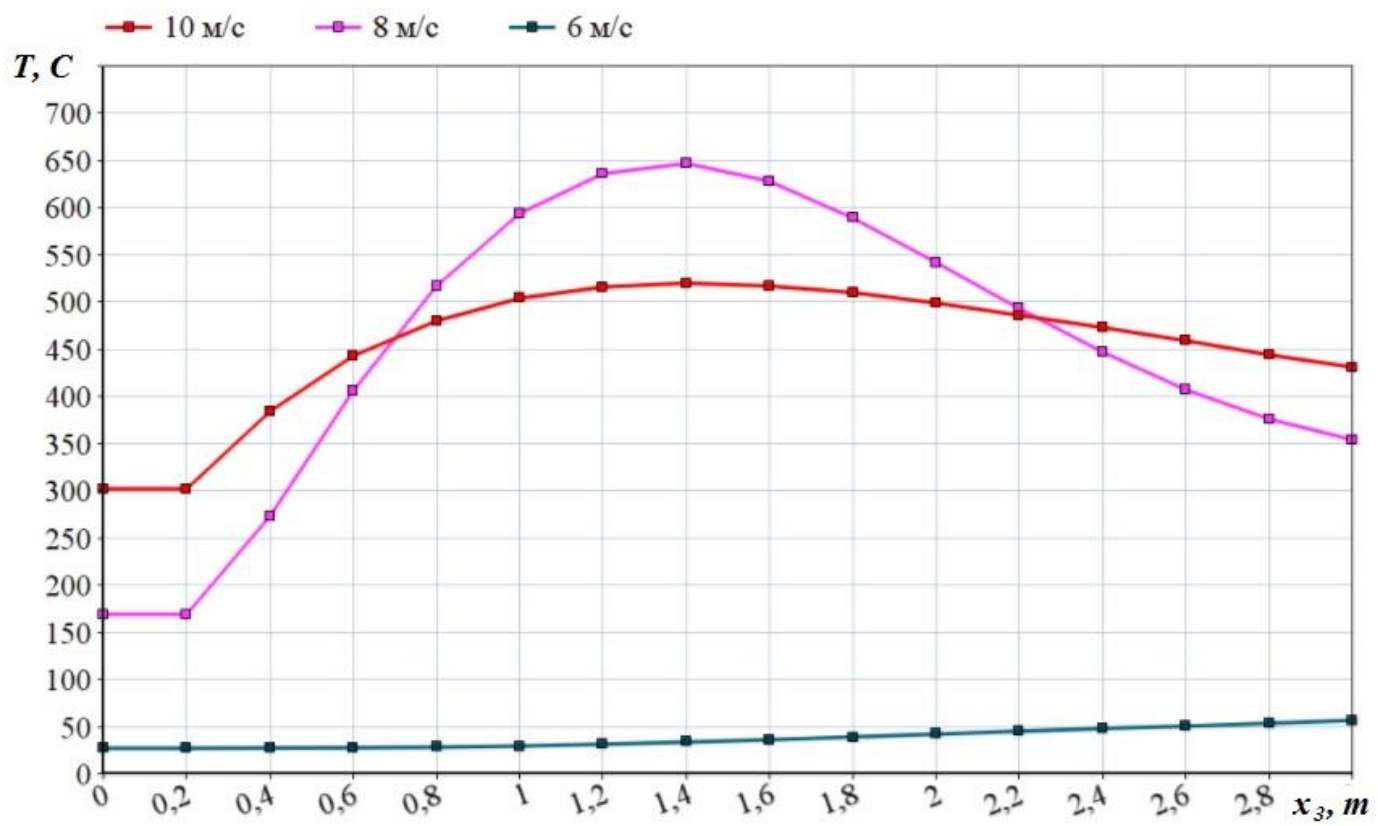

Figure 4 - The distribution of temperature on the wall of the building for three wind speed values. The distance between forest and building is $26 \mathrm{~m}$. 


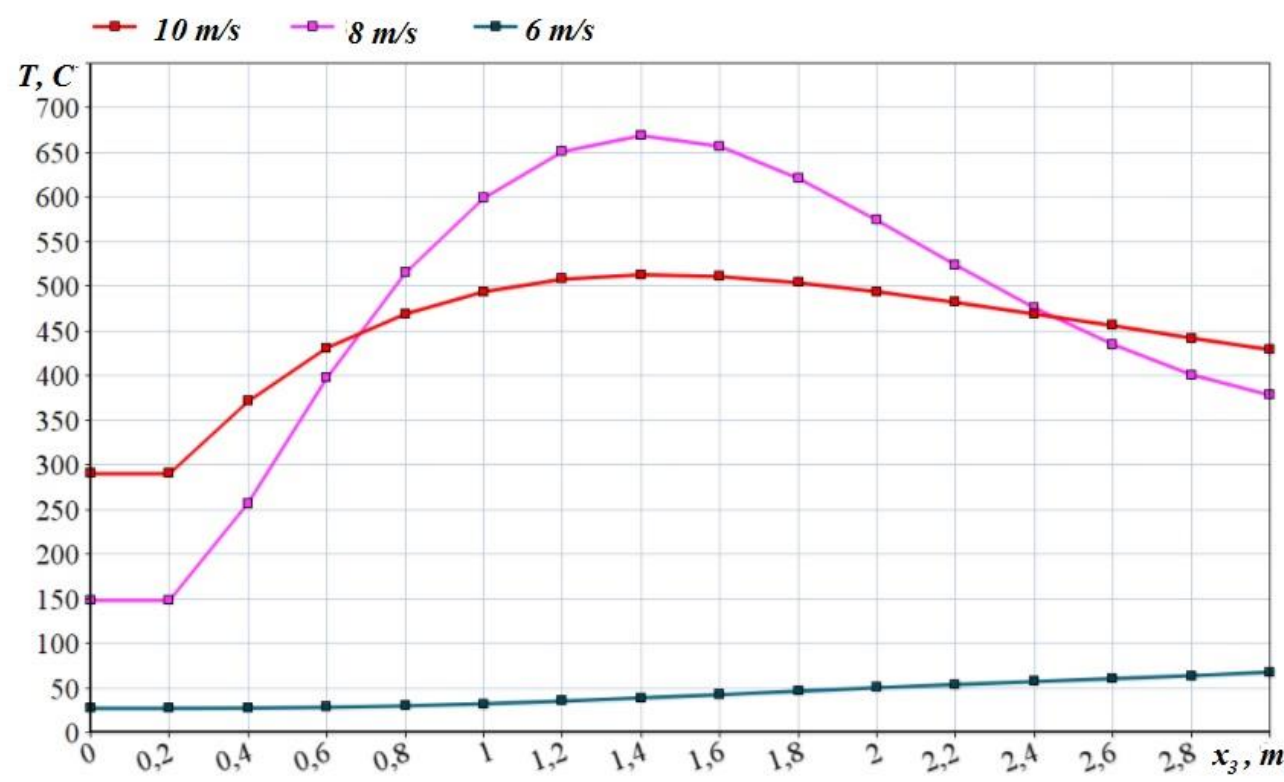

Figure 5 - The distribution of temperature on the wall of the building for three wind speed values. The distance between forest and building is $31 \mathrm{~m}$.

As a result of these calculations it was defined maximum safety distances between forest and building when the building would not have been ignited by forest fire (Fig. 6). The wind speed values increase from 6 to $14 \mathrm{~m} / \mathrm{s}$.

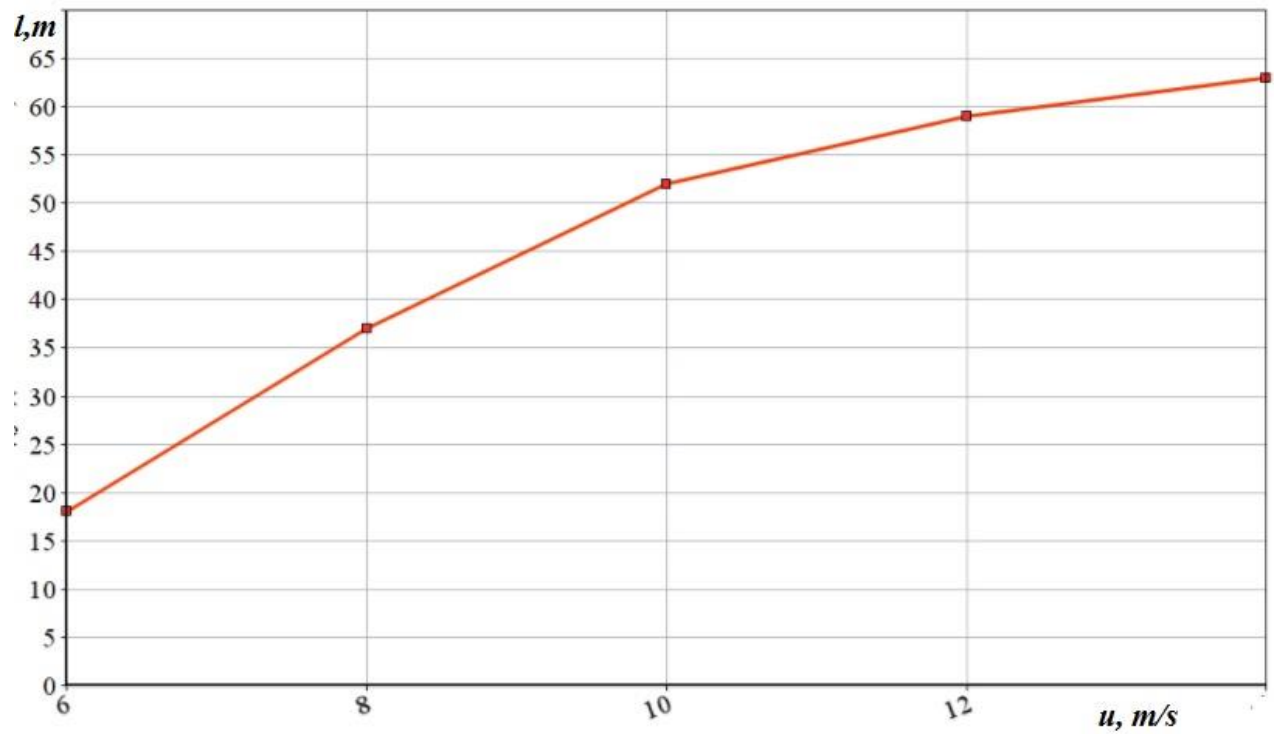

Figure 6 - The dependence of safety distances between forest and building as a function of wind speed values; H=3 $\mathrm{m}$.

Also, it was studied the influence of the height of building on the value of safety distances. When the height of building changes from 3 to $6 \mathrm{~m}$, the safety distances $l$ also increases (Figure 7) for different values of wind speed. 


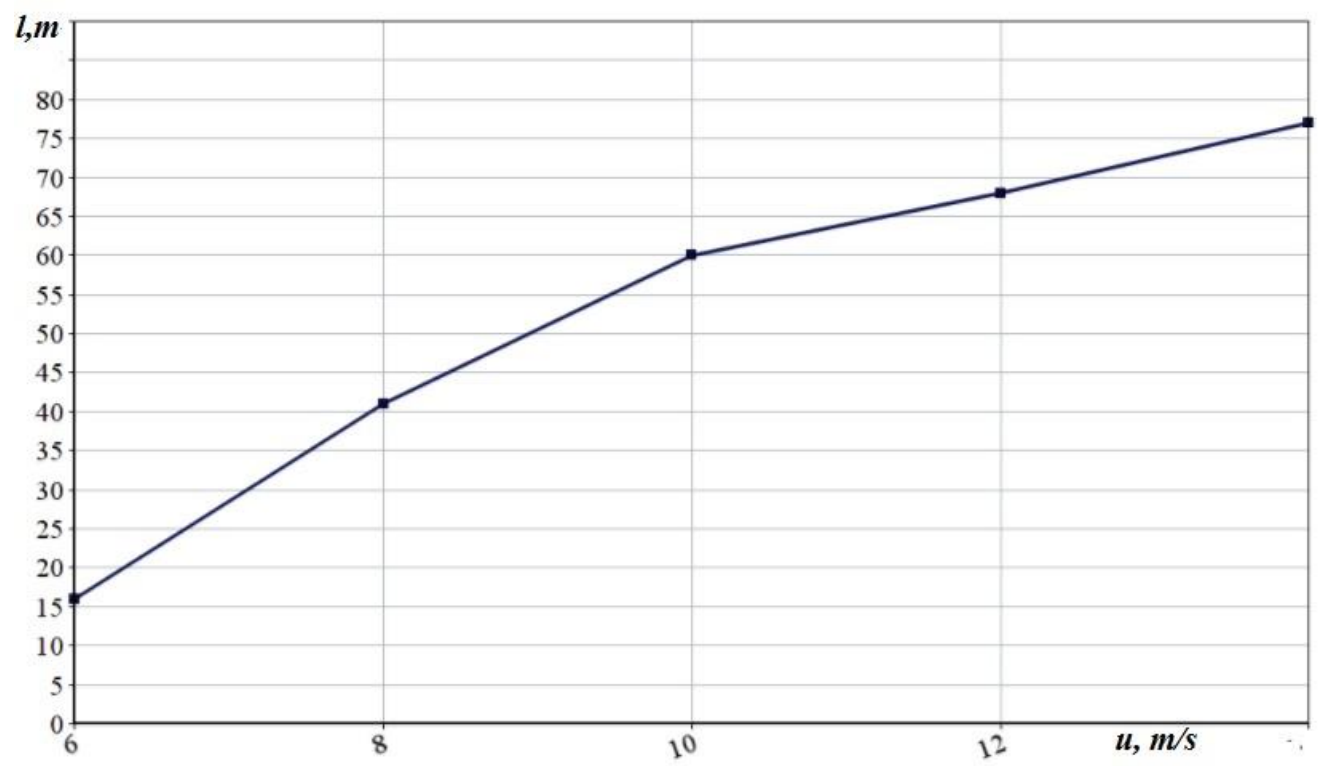

Figure 7 - The dependence of safety distances between forest and building as a function of wind speed values. $H=6 \mathrm{~m}$.

\section{Conclusion}

A mathematical model of wind-aided crown forest fires propagating through heterogeneous fuel beds has been performed. It takes into account the hydrodynamic aspects of the flow and uses Arrhenius kinetics to describe the basic physics and chemical processes of thermal decomposition heating, drying, pyrolysis, and combustion. Turbulence and radiation are considered in order to improve the physical insight. It allows to investigate the dynamics of the impact of forest fires on buildings under the influence of various external conditions: a) meteorology conditions (air temperature, wind velocity etc.), b) type (various kinds of forest combustible materials) and their state (load, moisture etc.). The calculations let to get the maximum distance from the fire to the building in which the object possible ignition. It has been found that the effect of increasing the wind speed is to increase the safety distances between forest and building. The increasing of building height is observed also led to increase the safety distances between forest and building. Specific experiments are also needed to obtain more reliable information on validation of further solution of this problem.

\section{Acknowledgments}

The paper was supported from Russian Foundation for Basic Research (project code: № 16-41700022 p_a) and within the framework of Tomsk Polytechnic University Competitiveness Enhancement Program grant.

\section{References}

Albini FA, Reinhardt ED (1995) Modeling ignition and burning rate of large woody natural fuels. International Journal of Wildland fire 5, 81-91.

Alexander ME (1979) Crown fire thresholds in exotic pine C.E. $10^{\text {th }}$ conference on fire and forest meteorology, Ottawa, Ontario. (Eds D. C. MacIver, H. Auld and R. Whitewood), 207-212.

Cruz MG., Alexander ME, Wakimoto RH (2002) Predicting crown fire behavior to support forest fire management decision-making, IV International Conference on Forest Fire Research, LusoCoimbra, Portugal. (Ed. D. X. Viegas), 11 [CD-ROM]. (Millpress). 
Grishin AM (1997) Mathematical modeling forest fire and new methods fighting them. (Publishing House of Tomsk University: Tomsk)

Morvan D, Dupuy JL. (2004) Modeling the propagation of wildfire through a mediterranean shrub using a multiphase formulation. Combustion and Flame 138, 199-210.

Patankar SV (1981) Numerical heat transfer and fluid flow. (Hemisphere Publishing Corporation: New York).

Rothermal RC (1972) Predicting behaviour and size of crown fires in the Northern Rocky Mountains, USDA Forest Service, Intermountain Forest and Range Experiment Station: Research Paper: INT438. (Ogden, UT).

Scott, JH, Reinhardt (2001) Assessing crown fire potential by linking models of surface and crown fire behavior, USDA Forest Service, Rocky Mountain Research Station. Fort Collins: Research Paper RMRS-RP-29.

Valendik EN, Mathveev PM, Safromov MA (1979) Large forest fires and fighting with them. (Science, Moscow) (in Russian)

Van Wagner CE (1977) Conditions for the start and spread of crown fire. Canadian Journal of Forest Research 7, 23-34.

Van Wagner CE (1999) Prediction of crown fire behavior in two stands of jack pine. Canadian Journal of Forest Research 23, 445-449.

Xanthopoulos G (1990) Development of a wildland crown fire initiation model, $\mathrm{PhD}$ thesis. (University of Montana: Montana) 